\title{
SUBJECTIVE ASSESSMENTS OF MULTIPLE INTELLIGENCES AMONG BOSNIAN AND TURKISH STUDENTS
}

\author{
Hakan Aydoğan, \\ Muğla Sıtkı Koçman University, Muğla, Turkey \\ E-mail: aydoganh@hotmail.com
}

Azamat Akbarov

International Burch University, Sarajevo, Bosnia and Herzegovina

E-mail: azamatakbar@yahoo.com

\begin{abstract}
General intelligence is a good predictor of academic achievement. However, according to Howard Gardner, there are several types of intelligence. They have to be considered in the educational context because education requires various skills and abilities to be employed so that students could be successful. The main aim of our study was to examine subjective assessments of multiple intelligences among adolescents as well as to investigate possible gender differences. The questionnaire called "Subjective assessment of multiple intelligences" (SAMI) was applied, which serves us to collect data from the targeted sample of 162 participants in Bosnia and Herzegovina. Firstly, the results showed non-significant gender differences. Secondly, only verbal/linguistic ability significantly correlated with the age of participants. Lastly, almost all correlational coefficients calculated between different types of intelligence were statistically significant. For example, subjective assessment of logical/ mathematical intelligence correlated with intrapersonal abilities/skills, verbal/linguistic intelligence correlated with visual/spatial intelligence, and musical abilities correlated with visual/spatial intelligence as well.
\end{abstract}

Key words: multiple intelligences, subjective assessment, gender differences, Bosnian students.

\section{Introduction}

The most famous definition of intelligence is that it is a phenomenon which refers to somebody's ability to adapt in new environments or conditions. It is both the strength and the speed of reasoning i.e. solving problems. Lots of theories emerged in order to explain and describe intelligence. The oldest (scientifically based) theory was proposed by Charles Spearman, a well-known statistician and psychologist. He stated that there is a general ability to think and act intelligently (e.g. Deary 2001; Chabris 2007; Sternberg 2009). He called this ability of the general factor of intelligence (or g- factor).

The second approach is Cattell-Horn theory of two types of intelligence. They believed there are two sorts of intelligence - fluid and crystallized (Horn \& Cattell 1967; Cattell 1963). The first one is mostly inherited and it can be interpreted like Spearman's general factor. The second one includes all experience, values, and skills which we acquire by our culture and society. Fluid intelligence starts to decrease in the adulthood, whereas crystallized intelligence continues to grow through the life span of individuals (Cattell 1987).

On the other hand, Wechsler (2003) made his intelligence tests based on the other two types of abilities - verbal and non-verbal (it comprises manipulation tasks, such as stacking cubes, sorting pictures etc.). 
PROBLEMS

OF EDUCATION

IN THE $21^{\text {st }}$ CENTURY

Volume 67,2015

Furthermore, Sternberg (1985) proposed the Triarchic theory of intelligence. He stated that we possess three kinds of cognitive abilities (Sternberg 1985, 1997): analytical (componential), contextual (practical) and creative (experiential). Finally, Howard Gardner, a professor of educational sciences, proposed the Theory of multiple intelligences. The most cited version of this theory considers seven types of intelligence (e.g. Gardner 1983, 1993, 1999): logical/ mathematical, visual/spatial, bodily/kinesthetic, verbal/linguistic, musical/ rhythmic, interpersonal, and intrapersonal abilities or skills. This theoretical approach sheds new light on intelligence, especially its domain-specific purposes. Meanwhile, Gardner (e.g. Gardner 2004) also added other two types of abilities - natural and existential intelligence. The first one comprises interest and ability for science and the other one is based on individual's ability of answering questions such as: "Is my life meaningful?" or "What is the purpose of living?" In this research, we analyzed the first seven types of cognitive abilities, because they were investigated the most.

Salehi and Gerami (2012) found that almost all multiple intelligences significantly correlate with each other. The mentioned research (Salehi \& Gerami 2012) also revealed that interpersonal intelligence was in a negative correlation with academic achievement of engineering students. Hajhashemi, Akef, and Anderson (2012) investigated, among other things, gender differences in multiple intelligences. They only found statistically significant differences in bodily/kinesthetic abilities (skills) in favor of women. Saricaoğlu and Arikan (2009) found significant differences just in case of linguistic intelligence (again, women had higher scores than men). This research also resulted in the following findings: musical intelligence positively correlated with English writing skills; on the other hand, intrapersonal, bodily, and spatial intelligence negatively correlated with the knowledge of grammar rules. Razmjoo (2008) conducted a study which revealed the following things: almost all types of intelligence were inter-correlated, there were no gender differences, and English proficiency is lower for those who scored high on bodily/kinesthetic intelligence scale. Koura \& Al-Hebaishi (2014) found that students who have high grades also report high levels of linguistic intelligence and students who have high levels of logical intelligence learn English grammar very easily. The study conducted by Fahim, Bagherkazemi, and Alemi (2010) revealed that levels of linguistic and logical intelligence correlated positively with TOEFL (the abbreviation of Test of English as a foreign language) reading scores and all types of multiple intelligences, taken together, accounted for $33.3 \%$ of TOEFL reading scores' variance. Shearer (2004) claimed that the knowledge and understanding of multiple intelligences by teachers can help them to improve and adjust their teaching skills and methods. As stated before, the theory of multiple intelligences is a very important scientific framework in cognitive psychology, educational psychology and pedagogy. Adolescents' subjective estimates of those abilities have impact on their school and academic performance, as well as on students' academic self-esteem.

\section{Problem of Research}

In this study, we were interested in the following: Are there gender differences in subjective assessments of multiple intelligences in the sample of adolescents? Does age correlate with subjective estimates of seven types of intelligence? Do different kinds of intelligences correlate between themselves? Based on our research questions and on the results of the previous studies in this field, we have defined these three hypotheses: 1) Gender differences will not be statistically significant, except for the bodily-kinesthetic and linguistic type of intelligence. 2) Because the age range is very narrow, we do not expect statistically significant correlation between age and subjective assessments of different kinds of intellectual abilities. 3) These estimates of seven types of intelligence will correlate among themselves and the correlation coefficients will be statistically significant. 


\section{Methodology of Research}

General Background of Research

This research was a quantitative one, with both correlational and quasi-experimental approaches. The scope of this research was to examine correlations among self-reported estimates of multiple intelligences and age of participants as well as to examine gender differences in multiple intelligences. It was conducted in May 2014 with the help of an online software for collecting and recording survey data.

\section{Subjects of Research}

Subjects of this research were 162 students from Bosnian high schools and universities. The mean age of participants was $\mathrm{M}=20.11$ and the measure of variability $\mathrm{SD}=1.78$. The age range was between 16 and 25 years. In Table 1, we can see the number of participants (frequencies) and the associated percent of total sample. As it can be seen (Table 1), there were 55 subjects (34\% of the total sample) who were 19 years old and they were the most numerous group of participants. On the other side, there was only one 16 year-old participant $(0.6 \%)$ and one 17 year-old subject ( $0.6 \%$ of the total sample). This study was conducted on the equal number of males and females (both: $\mathrm{n}=81$ or $50 \%$ of the total number of participants), in order to compare them properly.

Table 1. Distribution of the sample by participants' age.

\begin{tabular}{ccc}
\hline Age & Frequency $(\mathbf{f})$ & Percent $(\%)$ \\
\hline 16 & 1 & 0.6 \\
17 & 1 & 0.6 \\
18 & 22 & 13.6 \\
19 & 55 & 34.0 \\
20 & 26 & 16.0 \\
21 & 20 & 12.3 \\
22 & 17 & 10.5 \\
23 & 12 & 7.4 \\
24 & 6 & 3.7 \\
25 & 2 & 1.2 \\
\hline Total & 162 & 100.0 \\
\hline
\end{tabular}

\section{Instrument and Procedure}

For the purpose of conducting this research, we developed a seven-point Likert scale of assessment, which we called Subjective assessment of multiple intelligences (SAMI, Aydoğan, 2014). This instrument is based on Howard Gardner's influential theory of the structure of cognitive abilities. The mentioned psychological scale consisted of seven items (seven types of intellectual abilities), with short explanations provided for each ability: 1) Visual-spatial abilities (capacity to think in images and pictures, to visualize accurately and abstractly);2) Logical-mathematical abilities (think conceptually and abstractly, and capacity to find logical and numerical patterns quickly); 3) Bodily-kinesthetic abilities (ability to effectively control one's body movements and to handle objects skillfully); 4) Verbal-linguistic abilities (well-developed verbal skills and good sensitivity to the sounds, meanings and rhythms of words); 5) Musical abilities (ability to produce and appreciate rhythm, pitch and timber of voice and music); 6) Interpersonal abilities (capacity to detect and respond appropriately to the moods, motivations 
Hakan AYDOĞAN, Azamat AKBAROV. Subjective assessments of multiple intelligences among Bosnian and Turkish students

PROBLEMS

OF EDUCATION

IN THE $21^{\text {st }}$ CENTURY

Volume 67,2015

and desires of others i.e. to understand them), and 7) Intrapersonal abilities (capacity to be selfaware and in tune with inner feelings, values, beliefs and thinking processes; introspection and self-understanding). The participants had to pick the number which best represents the extent to which they think that they possess every particular ability. If they chose higher number, it would show their higher subjective estimate of these intelligences. Otherwise, they indicated lower subjective estimate of every intelligence type. We also added two questions, which gave us information on subjects' gender and age (i.e. socio-demographic variables).

The research was conducted via Internet. Every participant had the same instructions for filling the mentioned instrument (scale). It took them approximately 3-5 minutes to fill the scale which we gave to them. The answers were being recorded automatically. After that, the database was formed, with variables in the top row of its columns and the results in the following rows.

\section{Data Analysis}

The collected raw data were analyzed in MS Excel 2010 and SPSS 17.0 for Win. Our study was conducted in accordance with the code of professional ethics, and the participants' results are used, as it is obvious, only for research purposes. There were applied descriptive and inferential statistical techniques, in order to analyze the collected data. The results were displayed in tables and graphically.

\section{Results of Research}

First, the average results for seven types of intelligences (within the total sample) are going to be displayed, then, they will be displayed for males and females.

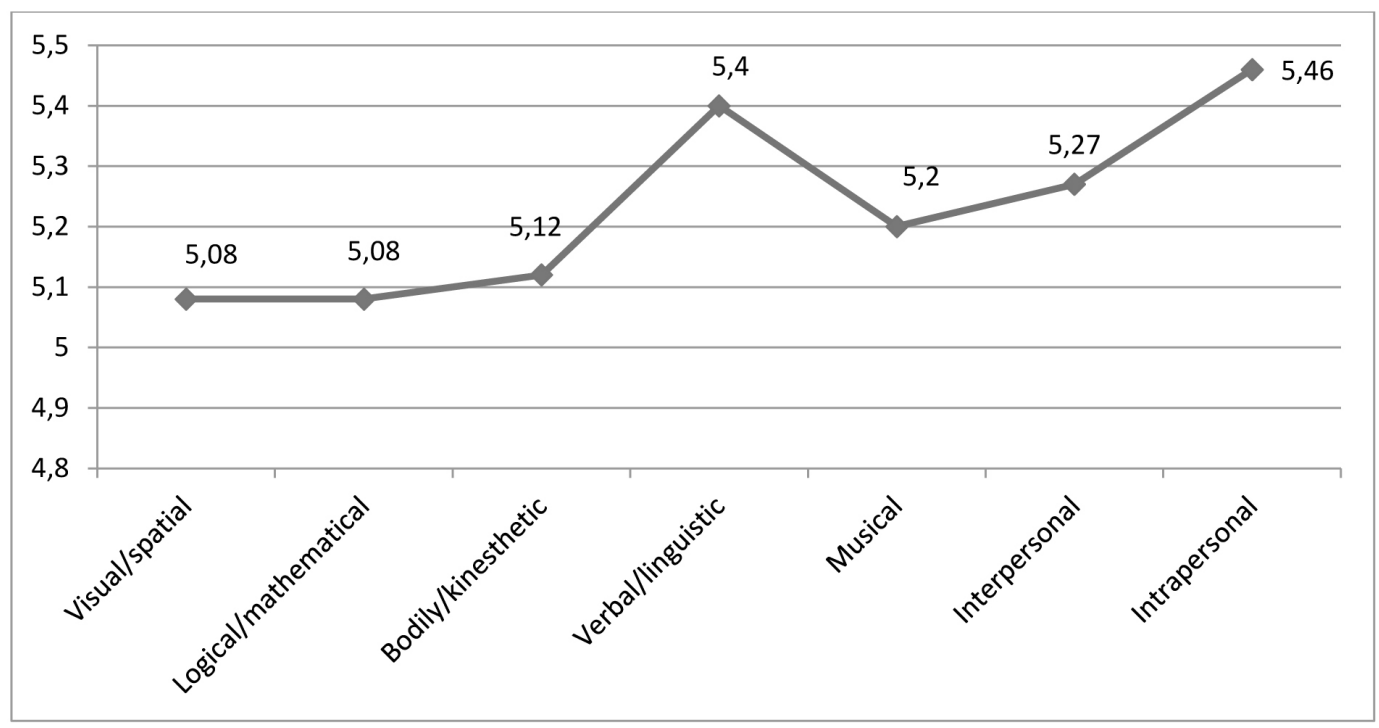

Figure 1: The multiple intelligences profile for the total sample.

It can be noticed (Figure 1) that each arithmetic mean is higher than the theoretical average value (i.e. higher than 4). Participants thought they possess intrapersonal abilities the most $(\mathrm{M}=5.46)$. The least possessed intellectual capacities, according to our subjects, are visual/ spatial and logical/mathematical abilities (for both of them: $M=5.08$ ). The second-ranked type 
of intelligence is verbal/linguistic ability $(\mathrm{M}=5.40)$, which is important for learning mother tongue and foreign languages (such as English). Interpersonal skills and abilities are less devel-

PROBLEMS OF EDUCATION IN THE $21^{\text {st }}$ CENTURY Volume 67,2015 oped $(\mathrm{M}=5.27)$ than intrapersonal skills abilities (among our participants and based on their subjective opinion). Participants estimated that their bodily/kinesthetic kind of intelligence (M $=5.12)$ was less developed than their musical intelligence $(\mathrm{M}=5.20)$.

The second figure is made in such a way that average results (arithmetic means) of males and females are displayed by lines of different types, in order to be compared in a visually effective way.

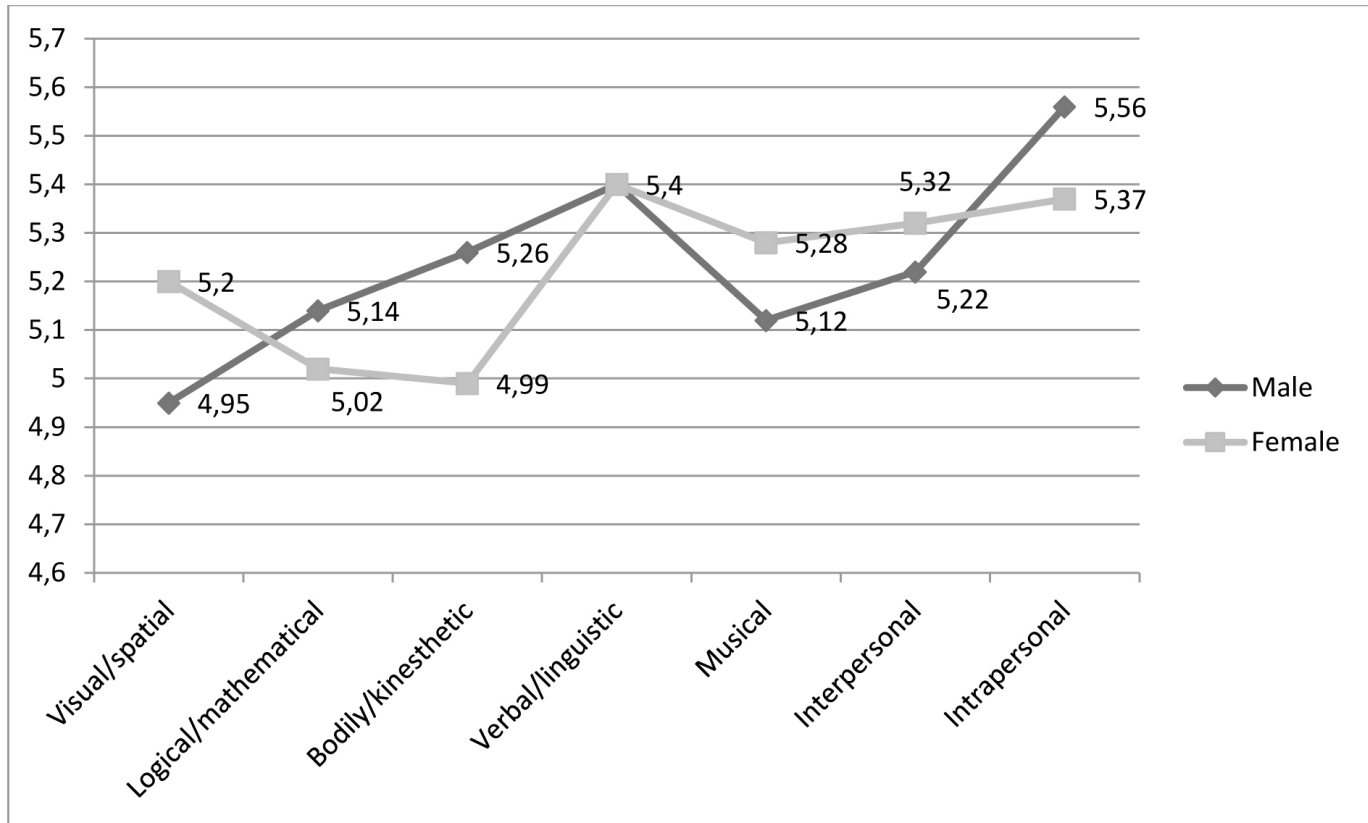

Figure 2: Gender profiles of multiple intelligences.

In the Figure 2, we see that males and females gave equal estimates of their verbal and linguistic abilities (for both: $M=5.40)$. Females had higher estimates $(M=5.20)$ of their visual/ spatial abilities, compared to males $(\mathrm{M}=4.95)$. They also scored higher on musical intelligence (females: $M=5.28$ vs. males: $M=5.12$ ) and interpersonal intelligence (females: $M=5.32$ vs. males: $\mathrm{M}=5.22$ ). On the other side, males' assessments are higher in the case of logical $/$ mathematical abilities (males: $M=5.14$, while females: $M=5.02$ ), bodily/kinesthetic intelligence (average result for males is $M=5.26$ vs. $M=4.99$ for females), and intrapersonal abilities (males, on average, scored $\mathrm{M}=5.56$ vs. females: $\mathrm{M}=5.37$ ).

To test exactly if these differences are statistically significant, we conducted t-test for independent samples. The results for every type of intelligence are shown in Table 2. We used the following labels: $\mathrm{M}$ - arithmetic mean (average value), $\mathrm{SD}$ - standard deviation (measure of variation), $\Delta \mathrm{M}$ - the difference between arithmetic means of males and females, SE $\Delta \mathrm{M}-$ standard error of the mentioned difference, $\mathrm{t}$ - the label for $\mathrm{t}$-statistic, $\mathrm{df}$ - degrees of freedom, and $p$ - the measure of statistical significance (it must be less than .05 to be pronounced as statistically significant). 
Hakan AYDOĞAN, Azamat AKBAROV. Subjective assessments of multiple intelligences among Bosnian and Turkish students

PROBLEMS

OF EDUCATION

IN THE 21 $21^{\text {st }}$ CENTURY
Volume 67, 2015

Table 2. Gender differences in multiple intelligences.

\begin{tabular}{|c|c|c|c|c|c|c|c|}
\hline Intelligences & M & SD & $\Delta \mathrm{M}$ & $\mathrm{SE}_{\Delta \mathrm{M}}$ & $\mathrm{t}$ & df & $\mathrm{p}$ \\
\hline Visual/spatial & $\begin{array}{l}4.95 \\
5.20\end{array}$ & $\begin{array}{l}1.22 \\
1.11\end{array}$ & -0.25 & 0.18 & -1.34 & 160 & .181 \\
\hline Logical/mathematical & $\begin{array}{l}5.14 \\
5.02\end{array}$ & $\begin{array}{l}0.96 \\
0.88\end{array}$ & 0.11 & 0.14 & 0.77 & 160 & .443 \\
\hline Bodily/kinesthetic & $\begin{array}{l}5.26 \\
4.99\end{array}$ & $\begin{array}{l}0.90 \\
0.94\end{array}$ & 0.27 & 0.14 & 1.87 & 160 & .063 \\
\hline Verbal//inguistic & $\begin{array}{l}5.41 \\
5.40\end{array}$ & $\begin{array}{l}1.09 \\
0.90\end{array}$ & 0.01 & 0.16 & 0.08 & 160 & .938 \\
\hline Musical & $\begin{array}{l}5.12 \\
5.28\end{array}$ & $\begin{array}{l}0.95 \\
1.03\end{array}$ & -0.16 & 0.16 & -1.03 & 160 & .304 \\
\hline Interpersonal & $\begin{array}{l}5.22 \\
5.32\end{array}$ & $\begin{array}{l}1.14 \\
1.05\end{array}$ & -0.10 & 0.17 & -0.57 & 160 & .567 \\
\hline Intrapersonal & $\begin{array}{l}5.56 \\
5.37\end{array}$ & $\begin{array}{l}1.08 \\
0.97\end{array}$ & 0.19 & 0.16 & 1.15 & 160 & .253 \\
\hline
\end{tabular}

In order to test the correlation between participants' age and the subjective estimates of seven intelligence types, we used Pearson's linear correlation coefficient (r). The results from this analysis are shown in Table 3.

Table 3. Correlations between age and multiple intelligences.

\begin{tabular}{lll}
\hline Age / multiple intelligences & Pearson's r & p-value \\
\hline Visual/spatial & .005 & .949 \\
Logical/mathematical & -.037 & .642 \\
Bodily/kinesthetic & .063 & .430 \\
Verbal/linguistic & -.209 & .008 \\
Musical & -.004 & .964 \\
Interpersonal & .080 & .313 \\
Intrapersonal & -.096 & .227 \\
\hline
\end{tabular}

As can be noticed (Table 3), there is only one correlation coefficient which is statistically significant (that of age and subjective assessment of verbal/linguistic intelligence).

Finally, we examined the relations between estimates of different kinds of abilities according to the multiple intelligences theory. The results are displayed in Table 4 . There were also calculated Pearson's correlation coefficients, as in the previous case. As we can notice in Table 4, more than a half of correlation coefficients are statistically significant. These results are explained in the discussion part of this article. 
Table 4. Matrix of inter-correlations between estimates of seven intelligences.

\begin{tabular}{|c|c|c|c|c|c|c|c|}
\hline & $\begin{array}{l}\text { Visual/ } \\
\text { spatial }\end{array}$ & $\begin{array}{l}\text { Logical/ } \\
\text { mathematical }\end{array}$ & $\begin{array}{l}\text { Bodily/ } \\
\text { kinesthetic }\end{array}$ & $\begin{array}{l}\text { Verbal/ } \\
\text { linguistic }\end{array}$ & Musical & Interpers. & Intrapers. \\
\hline $\begin{array}{l}\text { Visual/ } \\
\text { spatial }\end{array}$ & 1 & .075 & $.236^{* *}$ & $.611^{* \star *}$ & $.655^{\star \star *}$ & $.513^{\star \star *}$ & .013 \\
\hline $\begin{array}{l}\text { Logical/ } \\
\text { mathematical }\end{array}$ & .075 & 1 & -.012 & -.062 & .036 & .009 & $.703^{\star \star \star}$ \\
\hline $\begin{array}{l}\text { Bodily/ } \\
\text { kinesthetic }\end{array}$ & $.236^{\star *}$ & -.012 & 1 & $.193^{*}$ & $.154^{*}$ & $.412^{* * *}$ & $.252^{* *}$ \\
\hline $\begin{array}{l}\text { Verbal/ } \\
\text { linguistic }\end{array}$ & $.611^{\text {*** }}$ & -.062 & $.193^{*}$ & 1 & $.412^{\star * *}$ & $.252^{* *}$ & -.073 \\
\hline Musical & $.655^{\star * *}$ & .036 & $.154^{*}$ & $.412^{\star * *}$ & 1 & $.293^{\star \star *}$ & -.002 \\
\hline Interpersonal & $.513^{\star * *}$ & .009 & .138 & $.252^{* *}$ & $.293^{* * *}$ & 1 & -.035 \\
\hline Intrapersonal & .013 & $.703^{\star \star *}$ & .011 & -.073 & -.002 & -.035 & 1 \\
\hline
\end{tabular}

\section{Discussion}

First of all, despite the results shown in the previous figure (Fig 2), t-tests which we conducted reveal insufficient differences in arithmetic means of males and females. Hence, based on the data in Table 2, we can conclude that there are no statistically significant gender differences in multiple intelligences: visual/spatial $(\mathrm{t}(160)=-1.34, \mathrm{p}>.05)$, logical/ mathematical $(\mathrm{t}(160)=0.77, \mathrm{p}>.05)$, bodily/kinesthetic $(\mathrm{t}(160)=1.87, \mathrm{p}>.05)$, verbal/linguistic $(\mathrm{t}(160)$ $=0.08, \mathrm{p}>.05)$, musical $(\mathrm{t}(160)=-1.03, \mathrm{p}>.05)$, interpersonal $(\mathrm{t}(160)=-0.57, \mathrm{p}>.05)$, and intrapersonal $(\mathrm{t}(160)=1.15, \mathrm{p}>.05)$. In the case of bodily/kinesthetic abilities, the $\mathrm{p}-$ value is close to the marginal value $(p=.063$ and marginal value is $p=.05)$ and this result indicates that males possibly think that they have higher bodily/kinesthetic abilities than females (but, in our study, this finding was not statistically significant). In fact, (on average) males are physically stronger than females and that could be the explanation of their tendency to think that they are kinesthetically skilled and powerful. Therefore, we partially confirmed our first hypothesis (precisely, the most part of this hypothesis), because significant gender differences in multiple intelligences were not found. Our results were similar to those obtained by Razmjoo (2008). Furthermore, our findings only differ from the results obtained by Hajhashemi, Akef, and Anderson (2012) in the case of bodily-kinesthetic intelligence. Saricaoğlu and Arikan (2009) got similar results, but their study revealed gender differences in linguistic intelligence.

Next, it can be seen (Table 3) that only subjective estimate of verbal/linguistic intelligence correlates statistically significant with age $(\mathrm{r}=-.209, \mathrm{p}<.01)$. This coefficient is negative, which indicates that older participants think that they have lower verbal or linguistic abilities than younger subjects (as age increases, this estimated ability decreases and vice versa). Other correlation coefficients are statistically non-significant: visual/spatial $(\mathrm{r}=.005, \mathrm{p}>.05)$, logical $/$ mathematical $(r=-.037, p>.05)$, bodily/kinesthetic $(r=.063, p>.05)$, musical $(r=$ $-.004, \mathrm{p}>.05)$, interpersonal $(\mathrm{r}=.080, \mathrm{p}>.05)$, and intrapersonal abilities $(\mathrm{r}=-.096, \mathrm{p}>.05)$. Hence, based on the previous findings, we can almost totally accept our second hypothesis. That is, the second part of results (non-significant correlations between multiple intelligences and age, except for verbal/linguistic abilities) suggest that the period of adolescence is pretty stable in the aspect of self-assessed cognitive abilities and skills. It is contrary to the notion that this period of development is labeled as turbulent and unpredictable. 
PROBLEMS

OF EDUCATION

IN THE $21^{\text {st }}$ CENTURY

Volume 67,2015

Looking at the Table 4, it can be noticed that subjective estimate of one's visual/spatial abilities is in positive and statistically significant correlations with: bodily/kinesthetic intelligence $(\mathrm{r}=.236, \mathrm{p}<.05)$, verbal/linguistic abilities $(\mathrm{r}=.611, \mathrm{p}<.001)$, musical intelligence $(\mathrm{r}$ $=.655, \mathrm{p}<.001)$ and interpersonal abilities $(\mathrm{r}=.513, \mathrm{p}<.001)$. Subjective estimates of logical $/$ mathematical intelligence are in a high positive and statistically significant correlation with intrapersonal abilities $(\mathrm{r}=.703, \mathrm{p}<.001)$. These variables share $49.42 \%$ of their variance $(\mathrm{r} 2$ $=.4942$ ). Participants' estimations of their bodily/kinesthetic intelligence are in positive and statistically significant correlations with: verbal/linguistic abilities $(r=.193, p<.05)$, musical abilities $(\mathrm{r}=.154, \mathrm{p}<.05)$, intrapersonal intelligence $(\mathrm{r}=.412, \mathrm{p}<.001)$ and intrapersonal abilities $(\mathrm{r}=.252, \mathrm{p}<.01)$. Verbal/linguistic intelligence positively correlates with musical abilities $(\mathrm{r}=.412, \mathrm{p}<.001)$ and inter-personal type of intelligence $(\mathrm{r}=.252, \mathrm{p}<.01)$. At the end, musical intelligence is in a positive, statistically significant correlation with interpersonal abilities ( $\mathrm{r}$ $=.293, \mathrm{p}<.001$ ). Based on the previous findings (the significance of correlation coefficients), greater part of our third hypothesis was confirmed.

This (the last) part of results could be explained as follows. Musical intelligence means that students have good sense of pitch and rhythm (also, while learning new language). Interpersonal skills (social and emotional intelligence) can be understood as applying language knowledge through communication with others. Students who think that they have well-developed interpersonal intelligence are self-confident in social interactions and they are good at understanding others' emotions and non-verbal language, too. These claims are in accordance with the theoretical considerations of Howard Gardner $(1983,1993)$. Those who think that they have very good visual/spatial intelligence usually think in pictures and can form clear mental images of the outer world (in our context, they have visual learning style). In addition, they probably have dominant right brain hemisphere, as it was stated by Gardner (1999). Verbal/ linguistic ability is the most important type of intelligence for teaching and learning languages. The finding that it correlates with visual/spatial, bodily/kinesthetic, musical and interpersonal abilities and skills means that we, as teachers, need to work on developing these related skills among our students. This will improve their performance, academic achievement and dedication to learning topics and materials. Correlations between different types of intelligence indicate that our findings were in accordance to the results obtained by Salehi and Gerami (2012) as well as by Razmjoo (2008).

\section{Conclusions}

Regarding to our proposed hypotheses, we can conclude the following: 1) There were no statistically significant gender differences in subjective estimates of multiple intelligences. There were differences in average values of males' and females' results, but they were not large enough to be statistically significant. 2) Age only correlated with verbal/linguistic abilities. This relation was negative and small, but statistically significant. Older participants think that they have lower verbal/linguistic intelligence. 3) More than a half of correlation coefficients between multiple intelligences are statistically significant. Logical/mathematical intelligence correlated with intrapersonal abilities, while e.g. visual/spatial intelligence correlated with: bodily/ kinesthetic, verbal/linguistic, musical, and interpersonal abilities.

Therefore, this study shed light on relationships among participants' age and multiple intelligences, as well as relationships among multiple intelligences. It also revealed non-significant gender differences in self-assessed multiple intelligences.

It is suggested that future studies could find out how subjective estimates of multiple intelligences are related to participants' results on objective intelligence tests. Other researchers can also test differences in subjective assessments of multiple intelligences between successful and non-successful students. They can also investigate correlations between different types of 
intelligence and academic self-esteem, self-efficacy, personality traits, creativity, school grades/

academic performance, etc.

\section{Acknowledgement}

The authors of this article want to express their gratefulness to all participants who helped them to conduct this research.

\section{References}

Cattell, R. B. (1963). Theory of fluid and crystallized intelligence: A critical experiment. Journal of Educational Psychology, 5, 1-22.

Cattell, R. B. (1987). Intelligence: Its structure, growth, and action. New York: Elsevier Science.

Chabris, C. F. (2007). Cognitive and neurobiological mechanisms of the law of general intelligence. In M. J. Roberts (Ed.), Integrating the mind: Domain general versus domain specific processes in higher cognition (pp. 449-491). Hove, UK: Psychology Press.

Deary, I. J. (2001). Intelligence. A very short introduction. Oxford: Oxford University Press.

Fahim, M., Bagherkazemi, M., \& Alemi, M. (2010). The relationship between test takers' multiple intelligences and their performance on the reading sections of TOEFL and IELTS. BRAIN, 1, 1-14.

Gardner, H. (1983). Frames of mind: The Theory of multiple intelligences. New York: Basic Books.

Gardner, H. (1993). Multiple intelligences: The theory in practice. New York: Basic Books.

Gardner, H. (1999). Intelligence reframed: Multiple intelligences for the 21st century. New York: Basic Books.

Gardner, H. (2004). Changing minds: The art and science of changing our own and other people's minds. Watertown, MA: Harvard Business School Press.

Hajhashemi, K., Akef, K., \& Anderson, N. (2012). The relationship between multiple intelligences and reading proficiency of Iranian EFL students. World Applied Sciences Journal, 19, 1475-1483.

Horn, J. L., \& Cattell, R. B. (1967). Age differences in fluid and crystallized intelligence. Acta Psychologica, 26, 107-129.

Koura, A. A., \& Al-Hebaishi, M. (2014). The relationship between multiple intelligences, self-efficacy and academic achievement of Saudi gifted and regular intermediate students. Educational Research International, 3, 48-70.

Razmjoo, S. A. (2008). On the relationship between multiple intelligences and language proficiency. The Reading Matrix, 8, 155-174.

Salehi, M., \& Gerami, S. (2012). On the relationship between multiple intelligences and achievement among engineering students. English for Specific Purposes World, 35, 1-19.

Saricaoğlu, A., \& Arikan, A. (2009). A study of multiple intelligences, foreign language success and some selected variables. Journal of Theory and Practice in Education, 5, 110- 122.

Shearer, C. B. (2004). Using a multiple intelligences assessment to promote teacher development and student achievement. Teachers College Record, 106, 147-162.

Sternberg, R. J. (1985). Beyond IQ: A Triarchic theory of intelligence. Cambridge: Cambridge University Press.

Sternberg, R. J. (1997). A triarchic view of giftedness: Theory and practice. In N. Coleangelo \& G. A. Davis (Eds.), Handbook of Gifted Education (pp. 43-53). Boston, MA: Allyn and Bacon.

Sternberg, R. J. (2009). Cognitive psychology (5th Ed.). Belmont, CA: Wadsworth.

Wechsler, D. (2003). WISC-IV technical and interpretive manual. San Antonio, TX: Psychological Corporation. 
Hakan AYDOĞAN, Azamat AKBAROV. Subjective assessments of multiple intelligences among Bosnian and Turkish students

PROBLEMS

OF EDUCATION

IN THE $21^{\text {st }}$ CENTURY

Volume 67, 2015
Advised by Boris Aberšek, University of Maribor, Slovenia

Accepted: October 23, 2015

Received: October 01, 2015

Hakan Aydoğan

PhD, Lecturer, Muğla Sıtkı Koçman University, 48000 Muğla, Turkey.

E-mail: aydoganh@hotmail.com

Azamat Akbarov

$\mathrm{PhD}$, Associate Professor, International Burch University, 71000 Sarajevo, Bosnia and Herzegovina.

E-mail: azamatakbar@yahoo.com 